Rev. ANPOLL, n. 6/7, p. 131-140, jan./dez. 1999

\title{
CONSIDERAÇÕES PRELIMINARES PARA O ESTUDO DO ACENTO NO DISCURSO DO PORTUGUÊS (BRASILEIRO) E DO ESPANHOL
}

\begin{abstract}
RESUMO: Neste trabalho busca-se discutir questões preliminares sobre o acento de palavra e de oração no discurso falado em português, usando como referência um estudo anterior do espanhol (Simões 1996). No caso desse referido estudo do espanhol, analisaram-se os padrões temporais no discurso espontâneo de nove falantes nativos da variedade de espanhol considerada "padrão" nos EUA. A análise do espanhol teve como objetivo observar a função da duração em relação ao acento de palavra e de oração. A duração é tradicionalmente considerada como um dos três principais parâmetros físicos que compõem o acento. Os resultados confirmaram a opinião de alguns lingüistas de que a duração não é um correlato do acento em espanhol. Por outro lado, os resultados também mostraram que a duração tem uma função indicadora de qualquer evento significante no discurso, o que inclui não só o acento mas também qualquer outro fenômeno lingüístico significante. Esses resultados nos permitem analisar a duração de uma maneira diferente da que se faz tradicionalmente e também nos permite tecer considerações sobre o português. Portanto, a partir daqueles resultados, desenvolveu-se um trabalho preliminar para um estudo posterior no português e espanhol, sobre outros parâmetros considerados componentes universais do acento de palavra e de oração: a amplitude e a freqüência fundamental relativas dos sons da fala.
\end{abstract}

Antônio R. M. Simões *

PALAVRAS-CHAVE: acento; português; espanhol; contraste português-espanhol; duração; organização temporal; acento de palavra; acento de oração; acento de frase; fonética; estudo comparativo português espanhol.

* Department of Spanish and Portuguese, University of Kansas, EUA. 


\section{COMENTÁRIOS PRELIMINARES} A ntes de entrar nas considerações previstas nesta investigação "espanhol padrão" na $\Lambda$ mérica Latina. $\Lambda$ noção de "espanhol padrão" vem de uma prática comum em meios acadêmicos americanos onde o espanhol de referência para modelo nas salas de aula é, de uma maneira geral, o espanhol dos antigos vice-reinados da Espanha, ou seja as áreas onde hoje estão Bogotá, na Colômbia, Lima, no Peru e a cidade do México, no México. Por extensão também se consideram parte desse modelo imaginado, outras cidades dos altiplanos latinoamericanos como Quito, Guatemala e Guadalajara entre outras que em geral se encontram nos altiplanos latinoamericanos.

Nessas regiōes dos antigos vice-reinados coloniais se observa no espanhol falado entre a clases educadas um "consonantismo forte" ou "estável" (em espanhol, consonantismo fuerte). Em contraste, as outras regiões, regiōes em geral localizadas geograficamente em áreas de baixa altitude, se caracterizam por uma pronúncia de "consonantismo fraco" ou "inestável" (em espanhol, consonantismo débil). Entende-se por consonantismo estável o tipo de pronúncia em que não se eliminam nem se mudam as características principais de consoantes em posicão final de sílaba. Por exemplo, nessas regiōes de "consonantismo estável" se observa que palavras como "este" ou "pan", entre muitas outras, recebem uma pronúncia bem próxima daquilo que se lê na língua escrita e que em fonética representamos como [és.te] e [pan]. Por outro lado, em regiōes de consonantismo "inestável", como as ilhas do Caribe e outras regiōes situadas em áreas costeiras da América Latina, ou ainda em áreas geograficamente baixas, estas palavras são pronunciadas com várias mudanças das consoantes em posição final de silaba, dependendo do dialeto e mesmo do idioleto. Nguns dos muitos exemplos são os seguintes: 


$$
\begin{array}{ll}
\text { elisão da consoante fricativa alveolar: } & \text { [és.te] } \rightarrow \text { [é.te] } \\
\begin{array}{ll}
\text { aspiração da consoante fricativa alveolar: } \\
\text { elisão da consoante nasal alveolar }
\end{array} & \text { [és.te] } \rightarrow \text { [éh.te] } \\
\qquad \begin{array}{c}
\text { com nasalização da vogal anterior: } \\
\text { velarização da consoante nasal alveolar: }
\end{array} & \text { [pan] } \rightarrow \text { [pan] } \rightarrow \text { [pãh] }
\end{array}
$$

Quanto ao sistema vocálico do espanhol, de uma maneira geral, as vogais não se modificam, ou seja, não se centralizam como as vogais do inglês nem tampouco passam por elevaçöes vocálicas como no português. Normalmente, as cinco vogais do espanhol, há vários séculos, desde a época medieval, se caracterizam por serem estáveis, ou seja, não apresentam mudanças de qualidade em qualquer posição, tanto na palavra como na oração. Por outro lado, as vogais em português, e ainda bem mais em inglês, se caracterizam pela inestabilidade, pela mudança de qualidade no transcorrer do discurso, dependendo da posição em que aparecem na palavra e na frase. Essas mudanças serão menores ou maiores conforme os fatores que as influenciam no nível segmental e suprasegmental, isto é, prosódico.

Justamente esta estabilidade que mais caracteriza as vogais do espanhol é o que causa mais dificuldades para os falantes de português no aprendizado do espanhol. No caso do inglês a inestabilidade vocálica causa ainda mais dificuldades porque no discurso espontâneo o inglês se caracteriza por uma centralização vocálica em todas as posições átonas, um fenômeno muito freqüente que resulta numa alta ocorrência de vogais denominadas "schwas". No caso do português, uma ilustração interessante de elevação apareceu no filme "The Milagro Beanfield War" em que a figura da nossa radiante Sônia Braga aparece no início do filme falando inglês e espanhol "Okay... ¿Listos?". Nesse momento, na pronúncia da atriz se percebe uma elevação ou redução do "o" postônico semelhante a [lís.tus]. Isso serve para ilustrar a dificuldade que nós brasileiros temos com a pronúncia articulada e estável das vogais do espanhol. No caso de Sônia Braga, 
SIMÕES, Antônio R. M. Considerações preliminares para o estudo do acento...

se poderia sugerir uma interferência do português ou quem sabe até mesmo do espanhol mexicano-americano daquela região sudoeste dos EUA que se caracteriza por apresentar muita redução vocálica, talvez explicável pela possível influência do inglês.

Em português, tanto no nível da palavra como no nível da oração, a articulação dos núcleos vocálicos é limitada em posição postônica. Em espanhol, nessa mesma posição e especialmente em posição antes de pausa, no nível da oração, a articulação dos núcleos silábicos tende a ser reforçada, como se vê nos resultados do estudo de duração acima mencionado.

\section{O ACENTO NA FONÉTICA GERAL}

Ao entrarmos na questão do acento dentro de uma teoria geral da fonética, vamos deparar-nos com uma dificuldade em definir o que vem a ser o acento, embora exista um consenso entre foneticistas de que os três parâmetros básicos do acento, seja de palavra ou de oração, são a duração, a freqüência fundamental e a intensidade relativa do som ou fonema em questão (e.g. Belo 1949; Navarro Tomás 1967; Lehiste 1970; Ladefoged 1982, Delgado Martins 1982). Trata-se de uma tentativa de definição conhecida em fonética, mas que não vem a ser uma definição final. Fisicamente, ou em termos fonéticos, ainda não se sabe exatamente quais são nem como interatuam os componentes universais básicos que formam a nossa percepção daquilo que consideramos acento. Em fonética se compreende em parte esse fenômeno lingüístico, mas não se pode afirmar com segurança quais são os parâmetros físicos ou fonéticos na formação do acento. Trabalhos mais recentes buscam definir o acento de outra forma, como por exemplo, a definição do acento em termos da forma dos pulsos glóticos (Fant and Kruckenberg 1995; Sluijter et al 1995). Porém essas são propostas universais ainda limitadas. 
Embora a tendência seja considerar o tom como correlato principal do acento, se considera também a possibilidade de que a intensidade relativa e a duração tenha também um papel importante. Diferentes línguas parecem usar esses parâmetros de maneiras particulares a elas. No caso do português, por tradição, considera-se que o sinal ou parâmetro perceptivo principal do acento é a intensidade relativa (Delgado Martins 1982). Em espanhol, há duas tendências principais. Uma proposta clássica é a de Navarro Tomás (1967) em que se propõe, à semelhança do português, que o parâmetro principal do acento é a intensidade relativa. Por outro lado, a maioria dos estudos do espanhol propõem que a "entoação", ou seja a freqüência fundamental ou tom, é o principal correlato do acento (Bolinger e Hodapp 1961; Gili Gaya 1924; Contreras 1963; Quilis 1981).

Portanto, qualquer estudo sobre o acento teria que levar em consideração pelo menos esses três parâmetros básicos em análises acústica, fisiológica (articulatória) e perceptiva.

\section{O PAPEL DA DURAÇÃO NO DISCURSO EM PORTUGUÊS E ESPANHOL}

Desde um ponto de vista fonético, os padrões de tempo (duração) no discurso desempenham um papel tão significante que pode surpreender os estudiosos que não lhe dão importância devido à falta de contraste funcional ou fonêmico da duração em línguas como o português e o espanhol. Muitos estudos fonéticos dos padrões de tempo já atestaram a importância da duração no discurso (Klatt 1976; Klatt and Klatt 1990; Simões 1987; entre outros). Gunnar Fant, talvez os mais importante lingüista da nossa época, já havia notado que "o sinal acústico-perceptivo simples e fundamental da duração merece mais atenção do que convencionalmente se dá por ele" (em inglês, "the simple and fundamental cue of duration 
SIMÕES, Antônio R. M. Considerações preliminares para o estudo do acento...

deserves greater attention than is conventionally paid to it") (Fant 1970: 224).

Por outro lado, línguas em que supostamente a duração desempenha um papel fonêmico, como o inglês, leva alguns lingüistas a considerar a duração como o principal componente do acento (e.g. Ladefoged 1982) embora outros estejam em desacordo, como Bolinger (1958) que propõe o tom (em inglês, "pitch") como o componente mais importante na formação do acento.

Num estudo recente (Simões 1996), do qual evitarei os detalhes aqui e ao qual refiro o leitor para maiores dados assim como informações sobre metodologia, concluiu-se que a duração no discurso do espanhol desempenha um papel de indicador de eventos lingüísticos. Entenda-se por eventos toda e qualquer ocorrência na cadeia da fala: pausa para processamento da fala, fronteiras sintáticas, ritmo, entoação, enfim, tudo o que ocorre na fala inclusive o próprio acento, o tópico principal deste trabalho.

Essa função indicadora de eventos da duração mostrou na análise do espanhol que a última sílaba de qualquer palavra em espanhol antes de uma pausa é uma sílaba-chave no processamento da fala. A duração indica a existência de algum fenômeno lingüístico significante nesse ponto da cadeia lingüística.

Isso não quer dizer que o acento depende da duração, como se pode concluir nos inúmeros estudos sobre o acento. Por exemplo, no caso do espanhol, Bello (1949§32) correlaciona o acento [sic] com uma "levísima prolongación" da vogal, acompanhada de uma subida tonal. De maneira semelhante, Gili Gaya (1924: 169) vale-se do trabalho de descrição da quantidade vocálica em Navarro Tomás $(1916 ; 1917)$ para conseguir fazer medidas de intensidade e freqüência fundamental: "a vogal tônica é mais longa do que a vogal átona, e em função da quantidade localizamos o ponto exato do acento" (em espanhol, "la vocal acentuada es más larga que las inacentuadas, $y$ en función de la cantidad hemos precisado el lugar del acento"). Outros lingüistas como Contreras (1963) e Quilis (1981) tam- 
bém dão grande importância à duração como um dos correlatos principais do acento.

$\Lambda$ minha proposta, em relação ao acento de palavra e de oração, coincide com a proposta de Bolinger e Hodapp (1961) em que a duração não funciona como correlato principal do acento. Porém, busco não somente negar que a duração seja um correlato do acento, mas também explicar a função desse parâmetro. Portanto, $o$ acento em espanhol tem uma função indicadora de qualquer evento significante na cadeia de sons da fala.

$\Lambda$ s conseqüências desse tipo de interpretação mudam a maneira de ver da organização temporal do discurso, especialmente se considerarmos que essa interpretação também possa ser aplicada ao português e outras línguas naturais. Embora ainda não se tenha realizado com o português um trabalho instrumental como o que foi feito para o espanhol, acredito que se vá encontrar resultados semelhantes no discurso falado da nossa língua. E como resultado, como sempre se espera em estudos desta natureza, essas mesmas conclusões poderiam alcançar uma generalização em relação às outras línguas naturais.

\section{CONCLUSÃO}

$\Lambda$ linha de investigação apresentada neste trabalho produz resultados úteis, não só na elaboração de uma teoria fonética de línguas naturais como também em áreas aplicadas como o ensino de línguas estrangeiras, poesia, processamento da fala, entre outras. Por essa razão discutiu-se o acento dentro de uma teoria fonética, propondo que a duração desempenha um papel não de correlato do acento, mas sim de elemento indicador de qualquer fenômeno no discurso em português e espanhol. Quanto a uma aplicação dos resultados ao ensino do espanhol para estudantes cuja língua materna é o português, um professor de espanhol teria que levar em 
SIMÕES, Antônio R. M. Considerações preliminares para o estudo do acento...

conta a tendência do estudante brasileiro em modificar as vogais postônicas, e evitar essa elevação já que no espanhol considerado "padrão" essa tendência não deveria aparecer. Quanto à poesia, podemos explicar através da duração a decisão desde a época de Castilho (1908) de não se contar as sílabas de um verso como se fazia antes, à semelhança do espanhol, até o século XIX. Em espanhol, ainda hoje, as silabas de um verso são contadas até a última sílaba tônica mais uma sílaba adicional. Em espanhol isso ainda faz sentido, porque no espanhol falado se observa um esforço articulatório significante na pronúncia das silabas postônicas em posição anterior a pausas, ao passo que em português esse esforço normalmente não existe. Quanto à importância da duração em aplicações ao processamento da fala referiria o leitor aos trabalhos de um dos grandes foneticistas que passaram por nossa época, Dennis Klatt.

Portanto, a duração por mais simples e sem importância que possa . parecer, merece muita atenção, porque é através da duração que damos o primeiro passo para saber onde estão os pontos-chave do discurso. Em seguida, enfocamos nesses pontos para estudar em mais detalhes de que se tratam e finalmente tentar explicá-los. Não faria sentido minimizar a importância da duração em relação ao acento ou qualquer outro evento lingüístico no discurso. Não faria sentido, não só por causa dos resultados apresentados em inúmeros estudos sobre a duração, mas também porque qualquer evento físico está inevitavelmente ligado ao tempo.

ABSTRACT: This study treats preliminary questions regarding word and sentence stress in spoken discourse in Portuguese, using a previous study of Spanish (Simoes 1996) as reference. In that study, the temportal patterns of the spontaneous discourse of nine native speakers of Spanish were analyzed. The variety of Spanish used by those speakers is considered the most common model for Spanish in the US. That analysis focused on the function of duration in relation to word and sentence stress. Duration is traditionally considered one of the three main physical components of stress, but the study confirmed the claim of some linguists that duration is not a stress correlate in Spanish. On the other hand, those results 
Rev. ANPOLL, n. 6/7, p. 131-140, jan./dez. 1999

also showed that duration has a signaling function for any discourse event. In other words, duration will signal not only stress, but also other discourse events. Such results allow us to regard duration from a perspective different from the traditional one and extend our observations to other languages such as Portuguese. Therefore, from the results with Spanish, preliminaries considerations were developed for a future analysis of Spanish and Portuguese stress. This forthcoming analysis will include other stress components considered to be universal: relative amplitude and fundamental frequency of speech sounds.

KEYWORDS: stress; Portuguese; Spanish; Portuguese-Spanish contrast; duration; temporal organization; word-stress; sentence-stress; phrase-stress; phonetics; Spanish-Portuguese comparative study:

\section{BIBLIOGRAFIA}

BELLO, A. (1949) Gramática de la lengua castellana. Buenos Aires: Sopena.

BOLINGER, D.L. (1958) A theory of pitch accent in English. Word 14:109-49. . (1961) Contrastive accent and contrastive stress. Language, 37, 83-96.

BOLINGER, D.L. and M. HODAPP. (1961). Acento melódico, acento de intensidad. Boletín de Filología, 13:33-48.

CASTILHO, A.F. de (1908) Tratado de metrificação portuguesa. In Obras completas de A.F. de Castilho, LVI, 5. ed., v. 1. Lisboa, Portugal: Empreza da História de Portugal, Livraria Moderna.

CONTRERAS, H. (1963) Sobre el acento en español. Boletín de Filología, 15:223-37.

DELGADO MARTINS, M.R. (1982) Aspects de l'accent en portugais. Thèse de doctorat de 3ème. cycle (1977). Université de Strasbourg, Hamburger Phonetische Beiträge, 39, Helmut Buske Verlag, Hamburg.

FANT, G. (1970) Acoustic theory of speech production, 2. ed. The Hague: Mouton.

FANT, G. and A. KRUCKENBERG. (1995) The voice source in prosody. Proceedings of the International Congress of Phonetics Sciences, Stockholm, 2:622-25.

GILI GAYA, S. (1924) Influencia del acento y de las consonantes en las curvas de entonación. Revista de filología española, 11:154-77.

KIATT, D.H. (1976) Segmental duration in English. Journal of the Acoustical Society of America, 59, 1208-21. 
SIMÕES, Antônio R. M. Considerações preliminares para o estudo do acento...

KLATT, D.H. and L.C. KLATT. (1990) Analysis, synthesis, and perception of voice quality variations among female and male talkers.Journal of the Acoustical Society of $\Lambda$ merica, 87 (2), 820-57.

LADEFOGED, P. (1982) $\Lambda$ course in phonetics, 2. ed. San Diego, Ca.: Harcourt Brace Jovanovich.

LEHISTE, I. (1970) Suprasegmentals. Cambridge, Ma.: MTT Press.

LIEBERMAN, Ph.(1960) Some acoustic correlates of word stress in American English. Journal of the Acoustical Society of America, 32, 451-54.

NAVARRO TOMÁS, T. (1916) Cantidad de las vocales acentuadas. Revista de filología española, 3:378-408. 4:371-88.

. (1917) Cantidad de las vocales inacentuadas. Revista de filología española,

(1967) Manual de pronunciación española, $6^{\mathrm{a}}$ edición. Madrid: Consejo Superior de Investigaciones Científicas.

. (1983) Métrica española, $6^{\mathbf{a}}$ edición. Barcelona: Editorial Labor.

QUILIS, A. (1981) Fonética acústica de la lengua española. Madrid: Gredos.

SIMÕES, A.R.M. (1987) Temporal organization of Brazilian Portuguese vowels in continuous speech: an acoustical study, unpub. Diss. Austin, TX: University of Texas. $352-66$

. (1996) Duration as an element of lexical stress. In Hispanic Linguistics, 8:2,

SLUITJTER, A.M.C., S. SHATTUCK-HUFNAGEL, K.N. STEVENS, and V.J. VAN HEUVEN. (1995) Supralaryngeal resonance and glottal pulse shape, as correlates of stress and accent in English. Proceedings of the International Congress of Phonetics Sciences, Stockholm, 2:630-33. 